\title{
Sobre a arte de construir livros e significados (ou do ponto de vista do português)
}

Diego Beja Inglez de Souza

1 ANDRÉ TAVARES (Porto, 1976) é arquitecto pela Faculdade de Arquitectura da Universidade do Porto (2000), e autor dos livros Arquitectura antituberculose (Faup-publicações, 2005), Os Fantasmas de Serralves (Dafne, 2007), Novela Bufa do Ufanismo em Concreto (Dafne, 2009) e Duas obras de Januário Godinho em Ovar (Dafne, 2012). Foi director doJornal Arquitectos (20132015) e, com Diogo Seixas Lopes, curador geral da Trienal de Arquitectura de Lisboa 2016.
Resenha do livro de TAVARES, André ${ }^{1}$. Uma anatomia do livro de arquitetura. Porto/Zurich, Dafne/Canadian Center for Architecture, 2016 (simultaneamente publicado em inglês pela Lars Muller Publishers como The anatomy of the architectural book).

\begin{abstract}
O raciocínio de um arquitecto é moldado pela prática de arquitectura e pela necessidade constante de encontrar compromissos perante vontades contraditórias e contingências técnicas. Quando um arquitecto decide fazer um livro, apesar da sua eventual ignorância sobre a indústria da edição, sabe como encontrar as soluções necessárias para os problemas que enfrenta, sem receio de quebrar protocolos editoriais. Com frequência, os resultados são surpreendentes. (Tavares, 2016, p.9)
\end{abstract}

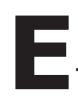

m Uma anatomia do livro de arquitetura, o arquiteto e editor português André Tavares 'disseca' através de um 'corte transversal' uma 'biblioteca infinita' de edições européias conservadas no Canadian Center for Architecture - CCA, que apoiou a pesquisa, desenvolvida como pós-doutorado pela Universidade do Minho e financiada pela Fundação de Ciência e Tecnologia portuguesa - FCT. Livros e edifícios são entendidos como 'manifestações de um conhecimento específico, que utiliza os materiais disponíveis para construir significados nos contextos sociais que justificam as suas formas e usos.'(p.21), habilmente apresentados a partir dos muitos pontos de encontro entre a teoria da arquitetura e a prática editorial.

1851 e 1925, anos 'vintage', ou seja, de 'colheitas editoriais excepcionais', numa metáfora emprestada do vocabulário da enologia que caracteriza especialmente as melhores safras dos vinhos da terra do autor - o Porto, seriam os pontos de partida para a cronologia deste livro e da empreitada investigativa. Mais do que coerência e certezas, encontramos nestes momentos ímpares impregnados de modernidade diversas pistas para outras possibilidades interpretativas dos marcos cronológicos da 'grande' história da arquitetura através de notícias e pesquisas relativamente recentes que vão alterando constantemente a maneira como percebemos, compreendemos e transmitimos os acontecimentos passados, como modelos, lições ou equívocos. 

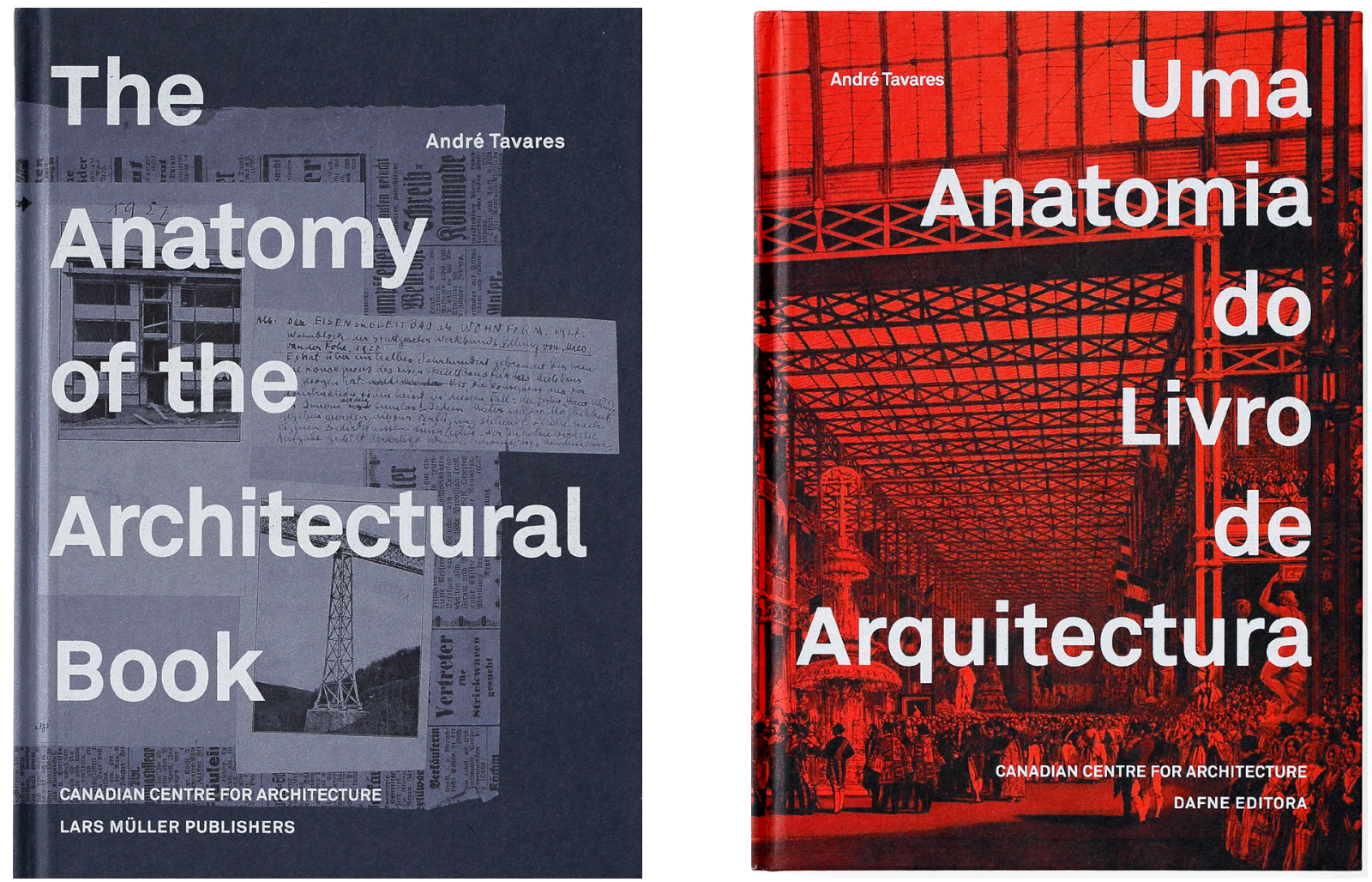

Figuras 01 e 02

Imagem ilustrativa do livro de André Tavares. Uma anatomia do livro de arquitetura.

Porto/Zurich, Dafne/Canadian Center for Architecture, 2016

Especial atenção é dada ao século XIX em torno dos movimentos entrecruzados de industrialização e popularização tanto da produção editorial quanto da crítica arquitetônica, o que reafirma o 'papel' do Palácio de Cristal e de suas diversas 'edições'. A partir deste marco incontornável da história da arquitetura moderna, André Tavares extrai diversas informações a partir do olhar do editor atento aos meandros da produção das representações dos edifícios e das transformações nas técnicas de impressão que ajudam a construir as imagens que circulam acerca dos exemplos e modelos do presente e do passado.

A descoberta da policromia da arquitetura grega e sua divulgação massiva através da cromolitografia abala a imagem alva e pura da principal matriz clássica, atravessando numa 'encruzilhada colorida' a trajetória do Palácio de Cristal, cujas fotografias a preto e branco neutralizam e apaziguam os tons e a intensidade das cores da estrutura e dos cintilantes objetos expostos. Transformado em reconstrução didática com objetivos de informação e entretenimento, o Palácio de Cristal reconstruído em Sydenham reunia em uma narrativa as representações dos principais momentos da história da arquitetura, como num guia de viagem através de 
uma experiência que poderia substituir a leitura de um livro, numa espécie de grand tour abreviado. O caso da reconstituição do Pátio dos Leões da Alhambra nos chamados Fine Arts Courts é revelador dos 'dilemas entre original e cópia' que levaram alguns visitantes ilustres à preferir a beleza ideal das reconstruções preservadas à autenticidade das peças reais, sujeitas aos rigores do tempo e da própria materialidade.

Como contraponto, delimitando um primeiro arco temporal que coincide com a consolidação de um 'movimento moderno' em arquitetura, internacional e relativamente coeso, André Tavares escrutina o 'desajeitado' Befreites wohnen, de Sigfried Giedion (1929). Trata-se de uma produção aparentemente contraditória, que versa sobre a produção industrial e moderna de uma 'habitação libertada' a partir de meios bastante artesanais de produção gráfica mas que se revelam eficientes na construção de um sentido, como campos experimentais para a 'interpenetração espacial' entre textos e imagens, desdobramento das leituras do historiador sobre a possibilidades da moderna arquitetura.

A quebra da bolsa de 1929, em data que coincide com a realização do 20 Congresso Internacional de Arquitetura Moderna em Frankfurt mas também com a publicação de Befreites Wohnen de Giedion se afirmam como marco para colocar limite numa primeira fase de desenvolvimento da arquitetura moderna e nas publicações que são objeto de análise, ainda que referências pontuais sejam feitas ao período pós-moderno através de Learning from Las Vegas de Venturi, Scott-Brown e Izenour. Na segunda parte do livro, o arco temporal se ampliará, regredindo aos textos fundadores da disciplina no mundo ocidental, passando pelos diversos tratados, releituras e anotações, a partir de Vitruvio.

As contribuições de Andrea Palladio, Leon Battista Alberti, Sebastiano Serlio, Giovanni Battista Piranesi, Philibert De L'Orme, Inigo Jones, Augustus Charles Pugin, Eugène Viollet-le-Duc, Gottfried Semper, Auguste Choisy, Humphry Repton, William Morris, Lás-

2 A estratégia narrativa já havia sido habilmente explorada em Novela Bufa do Ufanismo em Concreto Episódios avulsos das crises conjugais da arquitectura moderna no Brasil (1914-1943), 'uma viagem aos argumentos da construção de uma identidade para a arquitectura moderna brasileira', é uma das publicações resultantes do doutorado de André Tavares, que analisa a implantação da tecnologia do 'betão' armado em diversos contextos e programas. zlò Molohy-Nagy, El Lissitzky, Eric Mendelssohn e Le Corbusier, entre outros e não necessariamente nesta ordem, são apresentadas como capítulos mais ou menos avulsos da história da arquitetura ${ }^{2}$, através de uma abordagem original, construída sobre os personagens e episódios fundamentais da cultura profissional européia, veiculada e transmitida principalmente através de livros. André Tavares mobiliza também uma bibliografia igualmente infinita de pesquisas recentes e comentadores contemporâneos de cada um 
destes autores e obras, incorporando interpretações desmistificadoras e reveladoras das tessituras da profissão e das muitas condições de produção entre as idéias, os livros, os projetos e os canteiros. Os limites geográficos do 'corpus' vão um pouco além da Europa na segunda parte da Anatomia, onde são 'dissecadas' principalmente publicações européias, exceções (que confirmam a regra) feitas aos malsucedidos livros de Frank Lloyd Wright editados comercialmente na Alemanha e ao diário de bordo cinematográfico que registra a descoberta da Amerika por Eric Mendelsohn.

As categorias Textura, Superfície, Ritmo, Estrutura e Escala organizam os capítulos, apresentando uma miríade de referências especialmente selecionadas das produções de muitas safras que foram sedimentando o grosso do 'corpus' da cultura arquitetônica européia. Tratando-se de um livro construído por um arquiteto que é igualmente editor, nestas categorias podemos entrever as qualidades de um bom livro de arquitetura, evidência dos aprendizados da prática incorporados na produção teórica em uma dinâmica característica do conhecimento arquitetônico. Parafraseando o próprio André Tavares, acerca de seus achados e originais insights característicos do arquiteto que se propõe a construir uma obra editorial inovadora, "os resultados são surpreendentes". Através da noção de Textura, André Tavares nos apresenta o campo da 'marginalia', espaços em branco completados pelas anotações e desenhos dos aprendizes diretamente sobre as sucessivas edições dos tratados da arquitetura clássica. O que começa por ser um limitação editorial nos primórdios da impressão através de tipos móveis se torna possibilidade prática de exercício de interpretação imaginativa e concentrada observação, consoante com os modelos pedagógicos ligados à cultura renascentista. A impressão dos livros pode ser vista como exemplo precoce da divisão do trabalho a partir da introdução dos tipos móveis, que combinados com xilogravuras e posteriormente litogravuras, ajudaram a multiplicar o número de cópias e páginas, separando os trabalhadores segundo suas especializações, formação e procedimentos, de maneira análoga à transformação que se operou nos canteiros de obra a partir do renascimento e da emergência da figura do arquiteto como detentor de um saber especializado e simbolicamente valorizado.

O vanguardismo futurista atualiza o tema da textura nos primórdios do moderno através da curiosa 'arquitetura tipográfica' do italiano Fornunato Depero, autor de projetos de edifícios compostos de palavras escavadas nas fachadas, como no projeto do pavilhão para a feira de Monza de 1927, mesmo ano em que publica 
Depero futurista, livro que apresenta seus trabalhos e projetos através de 'construções gráficas complexas' ainda que um tanto 'desconexas', reunidas em uma publicação com estrutura e materialidade singulares.

Em Superfície, o foco é a construção da matéria cinzenta (livre tradução para 'grisaille', no original), por vezes monótona e impenetrável dos textos que se complementam com ilustrações e imagens no processo de construção de um argumento ou descrição de um modelo em arquitetura. A possibilidade de transformação da realidade através da arquitetura, opondo graficamente um antes e um depois da intervenção arquitetônica através de procedimentos comparativos enseja $m$ oposições, aproximações e contrastes na através de páginas duplas na obra editorial de Le Corbusier, Philibert De L'Orme e Humpty Repton como estratégia de convencimento de clientes ou discípulos. A densidade e o volume da reflexão acerca da profissão tomam o espaço das páginas, tornando-se espaços de debate e disputa em torno das concepções distintas da teoria e da transmissão das tradições compositivas e construtivas.

Após a revolução industrial destaca-se a contribuição de William Morris no campo teórico e editorial através da Kelmscott Press. Criada por 'puro divertimento', a editora acaba por publicar alguns dos textos essenciais de John Ruskin como The nature of Gothic (1892), além de diversos outros livros entendidos como objetos industriais carregados de prazer e felicidade no trabalho, ou seja, como obras de arte, de acordo com a concepção do próprio Morris.

Ritmo focaliza os processos de construção registrados em livro desde o renascimento, além dos diálogos entre as narrativas criadas pelo cinema e suas relações com a produção editorial vanguardista do início do século XX. O ritmo dos livros e seu espaço são transformados com o advento do cinema, que também vai revolucionar suas formas de montagem e sequências narrativas a partir das perspectivas renovadas apresentadas por livros de arquitetura. Percebe-se uma valorização renovada das qualidades editoriais e experimentais das publicações da Bauhaus, como Internationale Architektur (1925) de Walter Gropius e Malerei, Photographie, Film (1925) de Lászlò MoholyNagy, além da 'construção espacial' da compilação de poemas de Maiakóvski Dlia Golosa (1926). El Lissitzky, 'construtor do livro', aparece no mundo editorial com mais força e constância do que nas páginas dos manuais de história da arquitetura. 

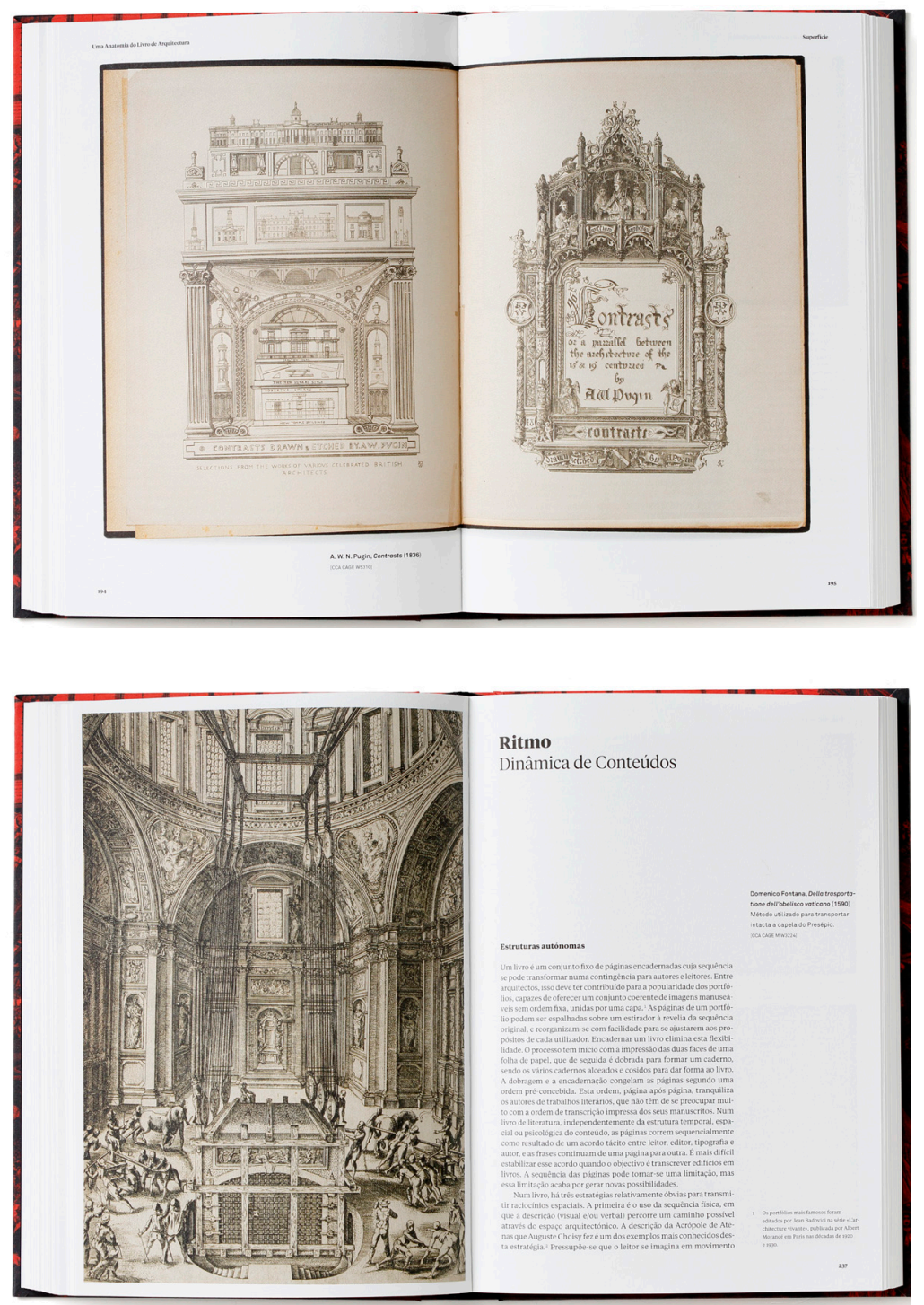

Figuras 03 e 04

Imagem ilustrativa do livro de André Tavares. Uma anatomia do livro de arquitetura.

Porto/Zurich, Dafne/Canadian Center for Architecture, 2016

Tanto os comentários de Serguei Eistentein acerca da descrição minuciosa da descoberta progressiva da Acrópole de Atenas por Auguste Choisy no texto 'Arquitetura e montagem' quanto as 'topografias tipográficas' de El Lissitzky evidenciam o contato e as 'contaminações' dos campos da produção de sentidos e narrativas de que são feitos filmes e livros, cujos ecos são percebidos claramente em filmes fundadores do cinema construtivista como Encouraçado Potemkin. Eric Mendelsohn parece incorporar e antecipar princípios de montagem cinematográfica que estavam sendo testadas por Eisenstein nos mesmo anos que publica Amerika, relato de sua viagem de navio a partir da chegada no porto de Nova York em 1924. Mendelsohn apresenta seu método para construir o livro, 
3 De acordo com o texto de apresentação da exposição no catálogo da mostra, "Da comunicação entre projecto e obra, da organização do tempo e do dinheiro, até à retórica política ou à excitação tecnológica, é na obra que tudo se joga". que teve grande sucesso na União Soviética, nação com a qual manterá intenso contato: "Escrevo através do olhar de um arquitecto, puramente visual. A partir dos edifícios, deduzo a história, transição, revolução e síntese. Síntese: Rússia e América - o futuro da Utopia!" (p.257).

Voltando à Renascença, o caso de Domenico Fontana, autor da proeza técnica e editorial Della trasportatione dell'obelisco vaticano (1590) expõe claramente um dos aspectos que muitas vezes parecem fugir dás páginas das histórias da arquitetura, qual seja, as etapas de conquista das encomendas dos projetos através dos procedimentos do desmonte, transporte e montagem do obelisco egípcio do Vaticano por 270 metros até a Praça de São Pedro, analisando as condições de produção, riscos inerentes envolvidos e transformação da solução técnica de um problema em realização simbólica da conquista de um desafio através da publicação da narrativa detalhada e ilustrada em livro.

O discurso e o ponto de vista dos acontecimentos e dos procedimentos a partir do olhar do arquiteto que os concebeu tende a ser tendenciosamente isento de contradições, como se pode supor da ressalva feita à esta narrativa ideal: "Esta coincidência entre estratégia preconcebida, mise en oeuvre bem sucedida e livro sugerem um retrato ideal: de facto, há outros relatos do evento que contradizem ligeiramente, ou suavizam, o tom épico da descrição de Fontana" (p.269) A atenção aos processos construtivos e ao trabalho parece ser uma preocupação constante no trabalho de André Tavares, que nos últimos anos dedicou-se também à curadoria geral da $4^{a}$ edição da Trienal de Arquitectura de Lisboa (inaugurada em outubro de 2016), sendo responsável também pelo módulo expositivo Obra, que propunha justamente um olhar para alguns episódios, projetos e personagens da história moderna e contemporânea a partir do canteiro de obras ${ }^{3}$.

A noção de Estrutura recebe e ordena as contribuições do racionalismo francês pós revolucionário através do papel da arquitetura no Dictionnaire raisonné des sciences, des arts et des métiers conhecido como Encyclopédie (1751-1772) de Diderot e D'Alembert. Responsável pela elaboração do verbete arquitetura e outros correlatos, personagem fundamental no ensino da arquitetura como 'arte criativa', Jacques-François Blondel deu especial atenção à descrição dos sistemas construtivos e do papel do arquiteto nas estruturas produtivas da construção civil, assim como Viollet-leDuc, principalmente através dos dez volumes do Dictionnaire raisonné de I'architecture française du XIe 
au XVIe siècle, espécie de 'alfabeto' ou manual que acaba por ajudar a definir a noção de arquitetura como linguagem, como gramática que orienta uma composição racional fundada no conhecimento anatômico da estrutura e das funções dos elementos constitutivos dos edifícios do passado.

Através do prisma da estrutura descobrimos as representações editoriais das experiências características das grande cidade: o Tallis's London Street View, publicado entre 1838 e 1840, inaugura um gênero de publicações das representações constantemente atualizadas das ruas e elevações das fachadas das ruas, como o Grand Architectural Panorama of London (1849) e o Rae's Panoramic Advertiser, da Filadélfia (1851), com objetivos de divulgação comercial que se desdobram em oportunidade virtual de flanar pelas grandes cidades, prefigurando ferramentas contemporâneas de exploração de cidades e metrópoles como as imagens do Google Street View.

Em Escala, são apresentados os principais elementos da consolidação dos manuais de composições arquitetônicas 'Les grands' et 'les Petites', como foram conhecidos na França do século XVIII e XIX as publicações de finalidade didática e instrumental de Jacques-François Blondel e Jean-Nicolas-Louis Durand, que ajudam hoje a compreender a transformação que se opera nestes anos nos procedimentos e elementos em jogo na concepção da obra arquitetônica. A lógica que orientava o ensino e concepção da arquitetura como gramática ou sistema compositivo ligado à tradições acadêmicas cristalizadas das publicações de Blondel e expressas nas noções de 'gênero', 'caráter' ou simplesmente o 'tipo' dos edifícios transforma-se em 'método', fundado por Durand na lógica interna do projeto, o que acabaria por abrir 'caminho a uma revolução na teoria da arquitectura' (p.347).

\section{Guia de uma viagem sem fim através de milhares de páginas}

Sem estragar as descobertas da leitura, altamente recomendável e certamente prazeirosa, podemos antecipar que esta anatomia se encerra em uma incisão que abre uma instigante reflexão acerca da arquitetura como linguagem de significação e registro de memórias coletivas das sociedades, que 'parte do mesmo impulso da escrita' (p.387). A profecia de um escritor célebre serve como pretexto para a resposta original de um arquiteto revolucionário, sob a forma de um edifício que manifesta de maneira literal as relações intrínsecas entre a construção de livros e das narrativas na arquitetura. 

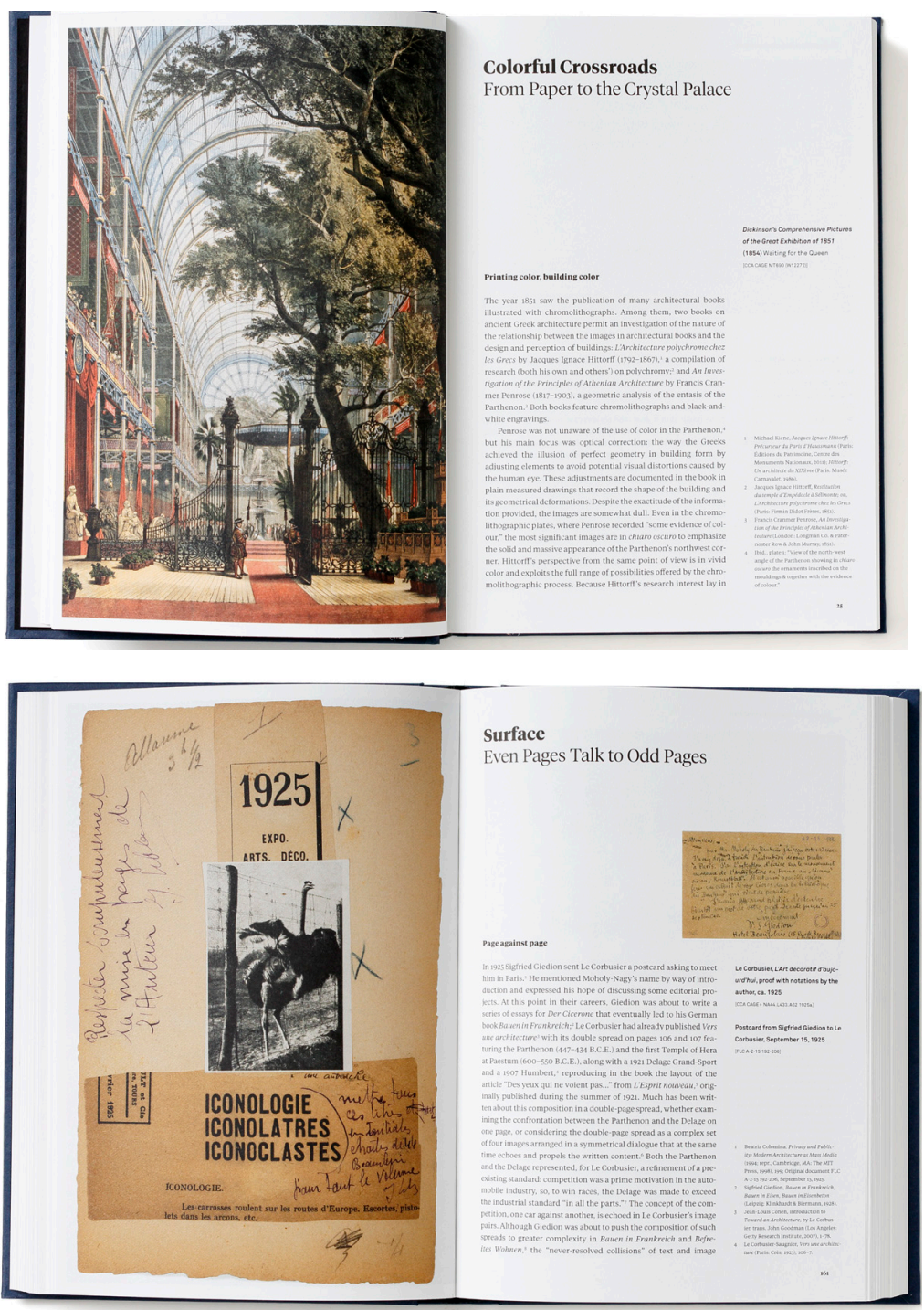

Figuras 05 e 06

Imagem ilustrativa do livro de André Tavares. Uma anatomia do livro de arquitetura.

Porto/Zurich, Dafne/Canadian Center for Architecture, 2016

É de se lamentar o fato da produção editorial portuguesa não estar mais integrada ao mercado brasileiro, em todos os campos mas especialmente na arquitetura. A competente e inovadora produção da Dafne editora, capitaneada por André e Domingos Tavares, seu pai e professor emérito da Faculdade de Arquitetura da Universidade do Porto, poderia ser republicada ou mesmo melhor distribuída no Brasil. A exceção, que confirma o argumento em favor do estreitamento das distâncias e enfrentamento dos procedimentos burocráticos que entravam os processos e encarecem os produtos é o ótimo Ricardo Severo da Lusitânia ao Piratininga - Da arqueologia portuguesa à arquitectura brasileira, de Joana Mello (2007), publicada pela Annablume e pela Dafne. Recentemente a Dafne, juntamente com a Lars Muller, lançou o livro de fotografias de Leonardo Finotti Uma Coleção de Arquitetura Moderna na América Latina, 
lacuna no mercado editorial brasileiro pela perspectiva geográfica ampliada, parcialmente preenchida por $O$ visível e o invisível na arquitetura moderna brasileira, do mesmo autor, com texto de José Tavares Correia de Lira, que analisa com profundidade alguns dos exemplares também inclusos na publicação portuguesa, convergência que demonstra a pertinência das empreitadas editoriais partilhadas entre Portugal e Brasil.

Para se restringir à produção dos Tavares, não restam dúvidas de que tanto as obras de André, como a Novela bufa do ufanismo em concreto armado, como o o recente Casas de brasileiro - Erudito e Popular na Arquitectura dos Torna-Viagem de Domingos Tavares ou António Francisco Lisboa - Classicismo no Novo Mundo, acerca do Aleijadinho, seriam contribuições originais e qualificadas ao debate de temas correlatos no panorama nacional, a partir de outras perspectivas, que dividem historicamente muitos pontos de contato. Tratam-se de contribuições originais e competentes para a constituição de um ainda algo desequilibrado campo da história da arquitetura no mundo lusófono, assim como Uma anatomia do livro de arquitectura.

Os diversos prêmios e indicações que as duas versões do livro de André Tavares vem conquistando atestam a qualidade da obra e a validade da aposta na dupla edição simultânea realizada pela Dafne Editora em parceria com a Lars Muller Publishers suíça, que torna a produção portuguesa imediatamente disponível ao público anglófono e a distribui para um mercado ampliado, eliminando a etapa da tradução e de uma nova edição. Sua publicação no Brasil seria uma oportunidade de retomar estas conexões, aproximando o público brasileiro das referências historiográficas clássicas e modernas européias a partir de uma perspectiva contemporânea e familiar, ao menos do ponto de vista do português como universo cultural comum, que historicamente carrega formas e linhas por meio das palavras e das obras através dos mares. 